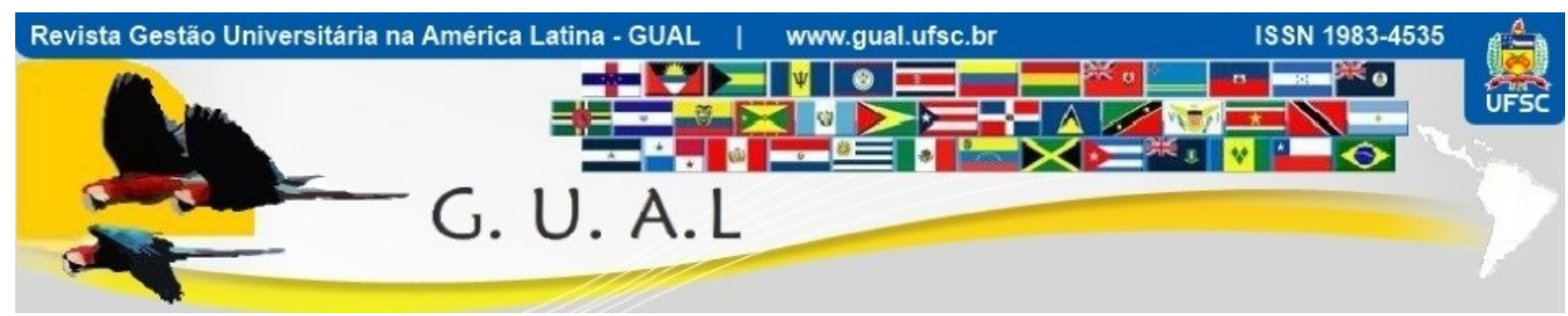

DOI: http://dx.doi.org/10.5007/1983-4535.2012v5n3p23

\title{
O PLANO DE DESENVOLVIMENTO INSTITUCIONAL E O PROJETO PEDAGÓGICO INSTITUCIONAL DE UNIVERSIDADES PÚBLICAS: LIMITES ORGANIZACIONAIS
}

\begin{abstract}
THE INSTITUTIONAL DEVELOPMENT PLAN AND THE INSTITUTIONAL EDUCATIONAL PROJECT OF PUBLIC UNIVERSITIES: ORGANIZATIONAL BOUNDARIES
\end{abstract}

Djair Picchiai, Doutor Escola de Administração de Empresas de São Paulo - Fundação Getulio Vargas (EAESP-FGV) Faculdade Campo Limpo Paulista (FACCAMP) djair.picchiai@,fgv.br

Recebido em 19/outubro/2012

Aprovado em 05/dezembro/2012

Sistema de Avaliação: Double Blind Review

Esta obra está sob uma Licença Creative Commons Atribuição-Uso. 


\title{
RESUMO
}

Observa-se a dificuldade de planejamento nas Universidades devido à falta de uma estrutura organizacional formalizada na área de gestão e execução de suas atividades. Os processos gerenciais e administrativos são executados de forma incipiente, prejudicando a capilaridade da estrutura quanto às informações e seus fluxos que dão forma e dinâmica à gestão. $\mathrm{O}$ objetivo do estudo foi analisar os Planos de Desenvolvimento Institucionais (PDIs) e Projetos Pedagógicos Institucionais (PPIs) de Universidades Públicas selecionadas. Constatou-se, por meio da leitura dos estatutos e regimentos gerais, que não se formalizam as atividades gerenciais da Universidade, tampouco as atribuições de seus órgãos administrativos e suas alçadas. Formalizam apenas, na maior parte das vezes, as competências dos órgãos superiores e dos colegiados, prejudicando a concepção e implantação dos planos da Universidade. $\mathrm{Na}$ literatura analisada encontram-se caminhos para a análise e propostas das questões levantadas de institucionalização e planejamento. Acredita-se que a execução do planejamento é o pontochave deste processo. As teorias explicam, em parte, os problemas encontrados, pois eles são muito específicos do setor público e das Universidades. Estas, por sua vez, exigem um tratamento diferenciado das teorias sobre gestão e planejamento.

Palavras-chave: Estrutura organizacional. Informação. Planejamento.

\begin{abstract}
It is noted the difficulty of planning in universities due to lack of a formalized organizational structure in the field of management and in the execution of its activities. The administrative and management processes are performed incidentally, impaired capillarity of the structure as to the information and its flows that will shape and make dynamic the management. The objective of the study was to analyze the Institutional Development Plans (PDIs) and Institutional Pedagogical Projects (PPIs) for selected public universities. It appears, by reading the general statutes and bylaws, that is does not formalize the management activities of the University and the assignments of its administrative organs and their offerings. It only formalizes, in most cases, the responsibilities of governing bodies and boards, damaging the conception and implementation of the plans in the University. In the literature reviewed it was found ways to analyze the issues raised and proposals for planning and institutionalizing. It is believed that the implementation of planning is the key point of this process. Theories explain partially the problems encountered because they are very specific of the public sector and universities. These, in turn, require a different treatment of theories about management and planning.
\end{abstract}

Keywords: Organizational structure. Information. Planning. 


\section{O PLANO DE DESENVOL VIMENTO INSTITUCIONAL E O PROJETO PEDAGÓGICO INSTITUCIONAL DE UNIVERSIDADES PÚBLICAS: LIMITES ORGANIZACIONAIS DOI: http://dx.doi.org/10.5007/1983-4535.2012v5n3p23}

\section{INTRODUÇÃO}

Esta pesquisa teve como objetivo estudar o Plano de Desenvolvimento Institucional (PDI) e o Projeto Pedagógico Institucional (PPI) de Universidades Públicas. Dado o tamanho, a complexidade e o processo de expansão das Universidades, no período de 2005 - 2010 focou-se na análise do plano e projeto, citados, preponderantemente no planejamento das Universidades, nas estruturas organizacionais, nas concepções, execuções e controles decorrentes. Analisaram-se as teorias organizacionais e de planejamento envolvidas na concepção dos planos e projetos e seus limites explicativos, como as dificuldades de suas aplicações nas Universidades Públicas. Estas têm características muito específicas quanto a sua forma de planejar e organizar.

Com o crescimento, as instituições federais caminham para uma situação em que terá que optar pela excelência de qualidade de seu ensino e pesquisa, que é sua tradição, ou massificação das suas atividades, principalmente as de ensino. As informações e projeções sobre orçamento, engenharia e pessoas demonstram essa situação. Isto, dado os atropelos e improvisações devido à falta de estrutura organizacional adequada, de recursos e de planejamento de suas atividades, considerando o tamanho e complexidade das Universidades em processo de expansão, principalmente para outros e novos campos de conhecimento.

Como contribuição teórica inicial têm-se os processos inerentes à institucionalização, a saber: habitualização, que corresponde à criação de novos arranjos estruturais em face de novos problemas enfrentados pela organização, assim como formalizá-los em políticas de uma ou de um conjunto de organizações com problemas iguais ou semelhantes. Entende-se por isso a adoção de práticas comuns impulsionadas por situações semelhantes vivenciadas pelas organizações; objetificação, envolvendo o desenvolvimento de um consenso social entre os tomadores de decisão da organização e compreende dois mecanismos diferentes de tomada de decisão: o primeiro está relacionado a possibilidade da organização utilizar evidências coletadas diretamente de fontes externas, tais como noticiários, manifestações da comunidades, observação direta, entre outras. Dessa forma pode-se dizer que a objetificação consiste no monitoramento que a organização faz dos competidores e de esforços para aumentar sua visibilidade; e o segundo mecanismo envolve a disseminação, que entende que quanto maior for a disseminação da escolha maior será a probabilidade de ser percebida como a melhor opção e menor influentes serão os julgamentos independentes sobre o valor da escolha; e por fim a sedimentação, para que o processo de institucionalização aconteça 
efetivamente é necessário que ocorra a sedimentação, ou seja, a continuidade histórica da estrutura organizacional, passando por várias gerações dos membros que compõe a organização, propagando-se virtualmente por todo o grupo de atores por longo período de tempo.

O planejamento necessita das estruturas organizacionais como um de seus elementos para sua implantação. A própria concepção do planejamento está atrelada ao contexto da infraestrutura. A implantação é responsável por boa parte dos processos das estratégias concebidas (HREBINIAK, 2006; MINTZBERG, 2004).

\subsection{OBJETIVO GERAL}

O objetivo geral foi analisar os Planos de Desenvolvimento Institucionais (PDIs) e Projetos Pedagógicos Institucionais (PPIs) de Universidades Públicas selecionadas. Buscou-se realizar uma análise gerencial e organizacional dos processos presentes, necessários na execução dos planos e projetos e, junto a isso, verificar como as teorias organizacionais, especificamente a teoria da institucionalização, podem ser analisadas neste contexto.

\subsection{JUSTIFICATIVA}

O conceito de planejamento estratégico é colocado como uma necessidade e solução para os problemas das Universidades por boa parte dos acadêmicos e corpo administrativo. As Universidades são sempre alertadas por não fazer uso de tal processo. Por outro lado, as teorias de planejamento oferecem conceitos e instrumentos para sua aplicação. O ponto é compreender suas limitações enquanto teoria, técnica gerencial, instrumental e identificar as barreiras e resistências ao planejamento estratégico quando aplicado a uma Universidade.

O planejamento estratégico é fundamental, mas não é uma solução única. A análise, a compreensão e a atuação sobre o comportamento das pessoas e a cultura organizacional devem fazer parte do processo de concepção e implantação do planejamento das mudanças necessárias. Estas são variáveis explicativas das principais limitações da implantação da mudança organizacional, da qual a implantação do processo de planejamento é um dos elementos. A cultura organizacional e o comportamento humano funcionam mais como barreiras do que como elementos facilitadores e impulsionadores do processo de planejamento. São resistências ao processo de mudança organizacional. 


\section{O PLANO DE DESENVOL VIMENTO INSTITUCIONAL E O PROJETO PEDAGÓGICO INSTITUCIONAL DE UNIVERSIDADES PÚBLICAS: LIMITES ORGANIZACIONAIS DOI: http://dx.doi.org/10.5007/1983-4535.2012v5n3p23}

O comportamento das pessoas nas organizações públicas é marcado pela estabilidade, dificultando a mudança e a profissionalização. A cultura organizacional nas instituições do setor público é definida por valores e crenças, que se formam desde o descobrimento do Brasil, passando pela época colonial, império, república velha, até os dias atuais. Pode-se dizer que os valores e crenças organizacionais são estabelecidos por meio da história administrativa. As Universidades, apesar de serem instituições mais novas, sofreram estas influências. Assim, relacionam-se duas características do setor público, a dificuldade de profissionalização da administração e sua cultura administrativa reativa.

O contraponto comportamental e cultural vem dos professores, com formação intelectual verticalizada e especializada muitas vezes feita no exterior, o que lhes dão uma autonomia muito grande nesta estrutura, e principalmente influenciando os princípios e normas de comportamento interno dos demais funcionários. Os professores trazem o novo para a instituição, buscam inovações em seus trabalhos de pesquisa e ensino para a sociedade. Neste contexto comportamental e cultural de administração pública encontram-se dois vetores: um com raízes culturais portuguesas, com fragmentos do estado patrimonial e do estado burocrático jurídico-formal e o outro com a cultura da autonomia e independência dos professores. Com estes dois vetores/barreiras falar em planejamento é um desafio.

A teoria da institucionalização da Universidade (habitualização, objetivação e sedimentação) é colocada como alternativa para discussão e melhor articulação dos interesses dos seus protagonistas. Estes desafios justificam a elaboração desta pesquisa, dada a sua importância, a complexidade do tema e as instituições estudadas.

\section{MÉTODO}

Fizeram parte da amostra estudada o Plano de Desenvolvimento Institucional (PDIs) e Projeto Pedagógico Institucional (PPIs) das seguintes Universidades Públicas: UFMG, UFSCAR, UNIFESP, UFBA e UFPE, e suas propostas, metodologias, conceitos utilizados, diretrizes e ações para as Universidades em questão.

Caracterizou-se como uma pesquisa teórica com base no levantamento bibliográfico, tomando como base a Universidade Federal de São Paulo (UNIFESP), que está em fase de expansão de seus Campi e cursos nos últimos seis anos.

Realizou-se uma breve análise do entendimento dos itens abordados, dado pelos PDIs e PPIs de algumas Universidades federais disponibilizados na internet. Assim como, foram 
realizadas análises dos seus estatutos e dos regimentos gerais. A amostra das Universidades foi por ordem de importância e tamanho.

Constitui-se de um estudo baseado em levantamento bibliográfico e documental além de apresentar-se como um estudo de caso de natureza exploratória (Yin, 2005).

\section{MODELO TEÓRICO}

Têm-se na literatura alguns modelos de administração e planejamento estratégico. Trabalhou-se com os modelos presentes em três obras: "Fazendo a estratégia funcionar" (HREBINIAK, 2006), o "Processo de planejamento estratégico" (MINTZBERG, 2004) e "O conceito de inteligência analítica como instrumento de análise" (DAVENPORT e HARRIS, 2007).

O planejamento estratégico é um processo contínuo. É um processo que envolve reflexão e ação. Ele procura atingir toda a Universidade, é um processo eminentemente participativo e integrativo entre os envolvidos.

O conceito de planejamento estratégico é sempre colocado como uma necessidade e solução para os problemas das Universidades. Verificou-se o seu entendimento e como ele é utilizado no dia a dia da Universidade. Procurou-se entender suas limitações enquanto técnica gerencial e seus limites quando aplicado a uma Universidade Pública Federal (CECÍLIO, 2001).

O planejamento estratégico possui algumas características importantes como o de fixar a direção, focalizar o esforço, definir a organização e provê-la com consistência necessária. O PDI e o PPI aparecem como dois elementos importantes do planejamento estratégico das Universidades. Fazer planejamento é uma atividade política, o planejamento não é neutro, ou melhor, não é uma técnica desprovida de objetividades quando de sua aplicação. Esta é uma das características a serem abordadas quando se utiliza modelos técnicos para analisar as Universidades Públicas. Outro ponto é que os problemas e os desafios organizacionais e gerenciais são maiores do que a técnica de planejamento possa resolver sozinha.

As áreas funcionais (engenharia, informática, orçamento, finanças, pessoas, manutenção, patrimônio, etc) tem suas alçadas e seu planejamento funcional. Assim como os campi, as escolas e demais unidades acadêmicas e administrativas também fazem seu planejamento, estes devem ser reconhecidos e incorporados no planejamento estratégico e institucional. 


\section{O PLANO DE DESENVOL VIMENTO INSTITUCIONAL E O PROJETO PEDAGÓGICO INSTITUCIONAL DE UNIVERSIDADES PÚBLICAS: LIMITES ORGANIZACIONAIS DOI: http://dx.doi.org/10.5007/1983-4535.2012v5n3p23}

O conceito de estruturas institucionais segundo Meyer e Rowan (1979) e Berger e Luckman (1967), é definido como estruturas que se tornaram institucionalizadas e que são consideradas pelos membros de um grupo social como eficazes e necessárias, como uma importante força causal para padrões estáveis de comportamento. Uma estrutura que não se traduz em ação é fundamentalmente, uma estrutura não social (GIDDENS, 1979). Uma maior institucionalização das atividades e estruturas em ação das Universidades é outro desafio a ser enfrentado, talvez o seu maior desafio, para viabilizá-los em um futuro próximo.

A Universidade deve trabalhar com as estruturas organizacionais e suas áreas de especialidades, aproveitar suas competências específicas, atribuindo-lhes poder de decisão sobre seus escopos de trabalho.

\subsection{AVALIAÇÃO DA LITERATURA BIBLIOGRÁFICA}

A falta de conhecimentos teóricos da função administrativa por parte dos dirigentes universitários faz com que a administração das Universidades seja desenvolvida de forma empírica, submetendo-a a riscos e ao conservadorismo. Fachin e Hardy (1996) afirmam que a administração universitária deve ser encarada como um ato pedagógico e não empresarial. Uma Universidade não pode ser vista como um imenso laboratório ou sala de aula. A matériaprima da Universidade, seus objetivos educacionais e sociais não podem ser comparados ao de uma indústria, dela resgatando apenas os elementos para se conseguir uma melhor organização interna, uma melhor distribuição de recursos. A Universidade é mais complexa, porém necessita de uma administração profissional.

Assim, o conhecimento das funções administrativas e a revisão da formação e qualificação dos dirigentes universitários são elementos necessários para a conquista da eficiência e eficácia na administração universitária (FACHIN e HARDY, 1996).

A reforma universitária de 1968 levou à abolição do poder dos catedráticos e o estabelecimento de departamentos e a atribuição da responsabilidade dos currículos a um órgão central. Acrescentaram-se também os conselhos departamentais e os colegiados de departamento. $\mathrm{O}$ objetivo da reforma era capacitar as universidades brasileiras a atingirem um padrão uniforme em todo o país, sem disparidade regional.

Em relação à análise da UFBA, Fachin e Hardy (1996) relata que a estratégia planejada não foi realizada em razão das manobras de atores políticos externos, já a arena política interna mostrou-se mais manejável do que a externa. Esses autores acreditam que a 
elaboração da estratégia acadêmica das Universidades, em geral, é difícil por conta da estruturação. A mudança se dá a partir da base da estrutura e os administradores têm um impacto limitado sobre a formulação de estratégias.

Ainda segundo Fachin e Hardy (1996), os líderes bem sucedidos são capazes de combinar a direção centralizada com um alto grau de autonomia acadêmica. Devem usar seu poder como catalisadores, criando e provocando a mudança e a inovação dentro da adhocracia.

Os autores ainda afirmam que o modelo de burocracia profissional enfatiza o desenvolvimento profissional, mas tende a focalizar a inovação limitando-se às estruturas existentes, em lugar de criar novas estruturas para acomodar iniciativas radicais. As burocracias profissionais não são, portanto, direcionáveis para a promoção de mudanças radicais.

Em algumas Universidades foi observado que existiam planos, porém faltava a estratégia. Uma estratégia transmite um padrão coerente de ações e planos e, no caso de uma Universidade, pode desempenhar um importante papel na motivação dos professores para atuar em direção a certos caminhos.

Sobre o ambiente externo e estilo de liderança, Fachin e Hardy (1996) colocam que todos os tipos de instituições devem prestar atenção ao ambiente externo tanto do ponto de visto político como financeiro. O papel financeiro e físico envolve as maneiras pelas quais os líderes podem proteger a instituição. Tal papel está ficando cada vez mais importante à medida que os líderes universitários tentam assegurar recursos provenientes do ambiente externo para suplementar os recursos recebidos de fontes do governo.

Os reitores, em geral, possuem maior controle sobre essas estratégias externas do que sobre a estratégia acadêmica. Assim, há potencial considerável para o reitor desenvolver estratégias criativas em seu papel como empreendedores, carregadores de recursos e arquitetos.

Todas as instituições federais ou estaduais sofrem severas restrições em virtude de pressões políticas externas, já que dependem de fontes governamentais para suas atividades de pesquisa. Em virtude de tal fato, os reitores agem como "malabaristas", gerenciando as relações de poder entre os grupos diferentes de interessados.

O reconhecimento da importância da diversidade parece ser uma importante forma de enxergar e pensar sobre Universidades no Brasil. É também uma constatação efetiva de como 
podem ser úteis ao conhecimento das Universidades o uso de modelos de análise organizacional mais amplo e que foram gerados em sua grande maioria fora do contexto de análise de organização universitária.

Segundo Fachin e Hardy (1996), o mito da uniformidade se une ao outro mito, o do centralismo, hoje em dia podem-se ver sinais de alguns caminhos em direção a uma maior descentralização do sistema universitário. O princípio de autonomia volta a ser definido como a capacidade das Universidades decidirem em aspectos acadêmicos, administrativos e financeiros com o mínimo de intervenção dos vários órgãos do governo central, em se tratando das Universidades públicas federais.

Os casos apresentados por Fachin e Hardy (1996) demonstraram como diferentes abordagens à liderança utilizadas pelos reitores das Universidades estudadas definiram caminhos organizacionais distintos. Além disso, explicaram como diferentes estilos de liderança ficaram ligados a um contexto universitário específico.

As Universidades formam suas estratégias a partir do exercício de uma liderança centralizada ou como resultado de formulação de políticas por parte do professorado. Há, assim, duas formas de provocar mudanças: a ação originada em nível central ou a ação resultante das forças descentralizadas. A efetividade dessas alternativas depende da natureza e do estágio de desenvolvimento de cada instituição em particular.

A implicação básica colocada por Fachin e Hardy (1996) está em “como mudar”, seja no contexto específico de uma nova Constituição, seja no sentido global, com a finalidade de estabelecer uma "saga" estratégica e um caráter distintivo de uma instituição em particular. O tema da uniformidade labora contra a caracterização desse caráter distintivo.

Compreender uma determinada Universidade ajuda a reunir idéias para um trabalho na direção da mudança. O ponto focal de mudança em cada configuração universitária tem que ser localizado. Em cada instituição, há aspectos que são mais estáveis e menos administráveis, ao lado de outros mais mutáveis. Agentes de mudança têm que localizar esses aspectos e mobilizar as forças de mudança, enquanto buscam deixar os outros aspectos inertes ou conformados.

A coerência entre vários aspectos no interior da organização acaba por resultar em uma variedade de configurações e estilo estratégicos. Em assim fazendo, há alguma riqueza na formulação de estratégias e formas estruturais das Universidades. Os líderes empresariais 


\section{O PLANO DE DESENVOL VIMENTO INSTITUCIONAL E O PROJETO PEDAGÓGICO INSTITUCIONAL DE UNIVERSIDADES PÚBLICAS: LIMITES ORGANIZACIONAIS DOI: http://dx.doi.org/10.5007/1983-4535.2012v5n3p23}

também necessitam relacionar a estratégia com a estrutura e determinar o estilo estratégico (PICCHIAI, 2008).

As organizações devem planejar para controlar e coordenar suas atividades e assegurar que o futuro seja levado em consideração. Além disso, devem planejar para ser racionais, pois a tomada de decisão formalizada é melhor que a não formalizada.

O modelo básico de processo de planejamento estratégico preconiza que sejam respeitadas as seguintes etapas: definição de objetivos, auditoria externa, avaliação da estratégia e operacionalização da estratégia.

Mintzberg e Quinn (2001) acreditam que a análise traz respostas exatas, a intuição nem sempre. A estratégia deve conciliar ambas, além disso, não é conseqüência do planejamento mais seu ponto de partida e ajuda a transformar os objetivos pretendidos em realidade.

\subsection{INTELIGÊNCIA ANALÍTICA. CONCEITO E ARCABOUÇO TEÓRICO. SUPOSIÇÃO E PROPOSTA DE ENCAMINHAMENTO DA QUESTÃO}

Uma instituição educacional necessita de sistemas flexíveis que permitam utilizar informações, gerar conhecimento e criar uma capacidade de competir de forma inteligente com um mercado cada vez mais competitivo. No setor público educacional ela permite um melhor entendimento dos contextos interno e externo das Universidades.

A inteligência analítica é a utilização extensiva de dados, análises quantitativas e estatísticas, modelos explicativos e preditivos e gestão baseada em fatos para orientar decisões e ações (DAVENPORT e HARRIS, 2007).

Davenport e Harris (2007) consideram fundamental o questionamento de dois pontos, são eles: que tipo de informação a organização deseja e para que tipo de decisão. Os autores citam também que um ponto crítico nas organizações é a falta de acesso direto ao cliente, a comunicação ocorre por meio de canais. Uma solução apontada pelos autores é a implantação na empresa de um Business Inteligence Competency Center.

Recomenda-se a criação de uma política de uso voltada ao conceito de inteligência analítica, pois uma dificuldade encontrada é que os gestores são pessoas, em sua maioria, não ligadas ao mundo "tecnológico"; assim observa-se uma dura realidade referente à utilização por parte de recursos humanos que não possuem a devida intimidade com a ferramenta tecnológica, o que leva a necessidade de capacitação dos gestores. 


\section{O PLANO DE DESENVOL VIMENTO INSTITUCIONAL E O PROJETO PEDAGÓGICO INSTITUCIONAL DE UNIVERSIDADES PÚBLICAS: LIMITES ORGANIZACIONAIS DOI: http://dx.doi.org/10.5007/1983-4535.2012v5n3p23}

Geralmente, usuários que utilizam a ferramenta de Business Inteligence (Inteligência Analítica) como forma de apoio à tomada de decisão, são aqueles que têm maior percepção dos resultados trazidos pela ferramenta, onde, por exemplo, são realizadas consultas até então impossíveis de serem feitas pelos usuários.

Ramos e Rezende (2004) destacam as vantagens e desvantagens encontradas na utilização do Business Intelligence (BI):

\begin{tabular}{l|c}
\hline \multicolumn{1}{c|}{ VANTAGENS } & DESVANTAGENS \\
\hline $\begin{array}{l}\text { - Resolução de necessidades do usuário de } \\
\text { forma on-line; }\end{array}$ & - Grande necessidade de treinamento; \\
\hline - Fácil acesso a dados e informações; & $\begin{array}{l}\text { - Possibilidade de consultas congestionarem a } \\
\text { rede de dados e o próprio banco de dados; }\end{array}$ \\
\hline - Controle de segurança efetivo; & - Falta de divulgação do produto internamente. \\
\hline - Interface com o Microsoft Excel; & \\
\hline $\begin{array}{l}\text { - Possibilidade de aliar cálculos/fórmulas e } \\
\text { regras de acesso à informação; }\end{array}$ & \\
\hline - Grande e significativo auxílio à tomada de \\
decisão.
\end{tabular}

As contribuições do projeto desenvolvido resgatam a real possibilidade da aplicação da ferramenta BI (e de seus recursos tecnológicos) nos serviços públicos e possibilitam que as organizações sejam beneficiadas pelos produtos gerados, principalmente pela geração das informações oportunas e dos conhecimentos por meio dos sistemas de informação.

As contribuições para as organizações públicas podem ser observadas nas aplicações dos recursos tecnológicos do BI nas atuações e na gestão dessas organizações. Os recursos do BI e as respectivas informações e conhecimentos podem também contribuir nas aplicações da New Public Management (NPM) nas organizações públicas.

Outra possibilidade, encontrada no relato de casos da área, é a construção de portais corporativos. Assim, a solução de portal corporativo possibilita às instituições melhorar sua produtividade e gerar eficiência ao oferecer aos funcionários, clientes e parceiros - através de um lugar único de acesso - todas as informações, aplicações e serviços necessários aos processos organizacionais.

A utilização da tecnologia da informação (TI) é considerada estratégica na gestão dos serviços de educação, pois tem como objetivo integrar todo um sistema de valores para a compreensão aos gestores das funções exercidas por cada unidade ou cada processo. Além disso, a integração dos elementos de TI permite que a organização desenvolva novas capacidades competitivas com base no conhecimento e aprendizado organizacional. Assim, a 


\section{O PLANO DE DESENVOL VIMENTO INSTITUCIONAL E O PROJETO PEDAGÓGICO INSTITUCIONAL DE UNIVERSIDADES PÚBLICAS: LIMITES ORGANIZACIONAIS DOI: http://dx.doi.org/10.5007/1983-4535.2012v5n3p23}

tomada de decisões apoiada por tecnologias de informação mais eficazes diminui substancialmente a subjetividade das escolhas estratégicas.

Quando dá disponibilização da informação, tem-se a questão: “eu não sabia o que eu queria ou precisava saber”. Para isto não basta apenas prover informações e indicadores de desempenho que geralmente refletem resultados já obtidos. É fundamental prover informações e conhecimentos estratégicos que levem a instituição a insights e possibilitem uma ação de forma mais efetiva sobre os resultados futuros.

Concluindo, um sistema de Business Intelligence permite uma visão objetiva da organização e da qualidade de atendimento aos clientes por indicadores alinhados aos objetivos estratégicos do negócio e à missão da instituição, obtidos de informações dispersas nas bases de dados existentes, como suporte ao processo de tomada de decisões estratégicas.

\section{REVISÃO DE LITERATURA: AVALIAÇÃO DO PROCESSO DE PLANEJAMENTO EM ALGUMAS UNIVERSIDADES}

Segue abaixo relatos de diagnósticos, experiências, teorias, metodologias e principais pontos do processo de planejamento em Universidades. Foram constatados muitos pontos comuns de problemas e desafios levantados, como também perspectivas de futuro idealizadas pelas comunidades das Universidades.

A metodologia adotada pela Universidade de Brasília (UnB) no processo de planejamento estratégico da Faculdade de Estudos Sociais Aplicados preconizou basicamente a homogeneização de percepções quanto aos conceitos utilizados, definição clara das tarefas e observância do tempo estabelecido para cada etapa do planejamento.

As etapas que levaram à composição da matriz de análise estratégica possibilitaram ao grupo refletir sobre as questões e problemas conjunturais enfrentados pela faculdade e também sobre aspectos positivos da sua estrutura operacional e funcional.

Outro ponto importante foi a análise sobre o contexto educacional brasileiro, que, no período da publicação do trabalho (2002) sofria algumas implicações decorrentes do fenômeno da globalização, principalmente no aspecto da economia, uma vez que esta trouxe uma nova dinâmica de mercado de trabalho e de desenvolvimento científico com o incremento da demanda por cursos de alta qualidade, maior especialização e maior diversidade. As novas exigências das empresas e o aumento da procura por profissionais mais versáteis e capacitados atiçaram a concorrência pelos cursos oferecidos pela UnB que, além 


\section{O PLANO DE DESENVOL VIMENTO INSTITUCIONAL E O PROJETO PEDAGÓGICO INSTITUCIONAL DE UNIVERSIDADES PÚBLICAS: LIMITES ORGANIZACIONAIS DOI: http://dx.doi.org/10.5007/1983-4535.2012v5n3p23}

de serem ofertados como ensino público gratuito, são considerados de excelente qualidade pelo mercado de trabalho.

Foi constatado pela Universidade um grande potencial devido à possibilidade de incorporação de novos e modernos recursos de tecnologia da informação, aliada ao potencial para a ampliação e diversificação de cursos e pesquisas e de realização de intercâmbios e parcerias, o que vêm ao encontro das necessidades de um mercado dinâmico e crescente. Estas oportunidades são potencializadas pelo reconhecido padrão de ensino e de formação do corpo docente e pelo bom nível de escolaridade dos alunos que ingressam na UnB.

Um dos principais problemas da faculdade em questão está relacionado à insuficiência de professores do quadro para o atendimento das demandas em seus departamentos. A defasagem dos salários dos professores vem provocando a evasão de talentos e um conseqüente declínio do número de docentes. Deste modo, é visível a falta de incentivo para atualização e aprimoramento dos professores. Essa falta de incentivo também pode ser percebida com relação ao quadro técnico-administrativo.

Para concluir, uma das estratégias adotadas foi a construção de instalações próprias e exclusivas para a faculdade abrigar, num mesmo espaço físico, todos os seus atuais cursos e também ter capacidade para incorporar novos cursos, deste modo, esta integração física possibilitaria, também, a desejada integração acadêmica.

O Instituto de Física de São Carlos (Universidade de São Paulo) em artigo cita a importância de contratação de consultor externo para que, durante o processo de planejamento estratégico, o nivelamento conceitual seja mais efetivo fazendo com que o grupo tenha a oportunidade de, a partir de um profissional externo experiente, obter orientações para aumentar as chances de sucesso do trabalho. Após esta etapa, reorganizou-se um banco de dados com aqueles que deveriam ser os principais doze indicadores de desempenho dos serviços da instituição. É provável que muito possa ser aproveitado do que já existe explícito na instituição.

O critério visibilidade deverá ser tratado com cuidado, onde todo o processo de construção do planejamento estratégico deve ser acompanhado por alunos, professores e funcionários. Isto ocorrerá através da construção de uma página na internet, que deve ser atualizada a cada etapa da elaboração, ou ainda, através de seminários, palestras explicativas, dando transparência ao processo. Inclusive, é importante que os dados do diagnóstico 


\section{O PLANO DE DESENVOL VIMENTO INSTITUCIONAL E O PROJETO PEDAGÓGICO INSTITUCIONAL DE UNIVERSIDADES PÚBLICAS: LIMITES ORGANIZACIONAIS DOI: http://dx.doi.org/10.5007/1983-4535.2012v5n3p23}

institucional bem como o plano de metas, estejam visíveis aos olhos daqueles que fazem parte da instituição.

Para concluir, "Instituições de ensino superior que não repensarem os seus papéis, responsabilidades e estruturas, podem esperar tempos difíceis na próxima década e próximas gerações. Algumas não irão sobreviver. Muitas terão que fazer muito mais com bem menos" Glassman e Rossy, n.d. (apud LERNER, 1999).

Em sua tentativa inicial de realizar um processo de planejamento estratégico, a Universidade Federal de São Carlos (UFSCar) encontrou algumas dificuldades relacionadas à ausência de formação de equipe em assuntos de planejamento e monitoramento dos objetivos e atividades frente ao porte do projeto. Outra importante lacuna foi a falta de estabelecimento de indicadores de desempenho, ou seja, não havia mecanismos para medir se as metas foram atingidas.

Já na segunda fase, a metodologia adotada viabilizou maiores debates e participação das partes interessadas. Utilizou-se o modelo adaptado do Planejamento Estratégico Situacional. Para tanto, houve a definição de dois eixos:

a) Projeto acadêmico integrado e

b) Universidade gerida de forma planejada, participativa e sustentável.

Neste modelo, foram analisados os principais pontos fracos da Universidade e construída uma árvore de problemas. Nesta construção foi possível estabelecer a relação de causa/ação, inter-relação e hierarquia entre os problemas identificados.

$\mathrm{Na}$ etapa posterior, do desdobramento dos planos, foram realizadas reuniões onde havia um acompanhamento dos resultados dos indicadores estabelecidos na fase inicial do planejamento.

Um eixo importante definido pela Universidade foi intitulado: "Universidade gerida de modo planejado, participativo e sustentável”. Assim, o detalhamento deste eixo viabilizou a definição das grandes diretrizes do Plano de Desenvolvimento Institucional (PDI).

Na realização do PDI foram considerados os aspectos acadêmicos, organizacionais, ambientais e físicos, que se inter-relacionam. Trata-se de um modelo aberto que permite a construção pela comunidade e a tomada de decisão cabe ao colegiado. 


\section{O PLANO DE DESENVOL VIMENTO INSTITUCIONAL E O PROJETO PEDAGÓGICO INSTITUCIONAL DE UNIVERSIDADES PÚBLICAS: LIMITES ORGANIZACIONAIS DOI: http://dx.doi.org/10.5007/1983-4535.2012v5n3p23}

O grande desafio de todo processo de elaboração foi o envolvimento efetivo da comunidade nas discussões e no estabelecimento do plano, garantindo com esta ação maior qualidade e legitimidade ao processo. Além disso, as informações do PDI ficaram disponíveis na homepage e, com frequência, informações diretas são enviadas para cada membro da comunidade. Todos os membros da Universidade receberam, nominalmente, um livreto, com uma carta do Reitor explicando o PDI.

Uma barreira importante enfrentada na execução do processo foi o problema de relacionamento entre os setores, faltando uma definição clara de responsabilidades.

\section{INSTRUMENTOS: PLANO DE DESENVOLVIMENTO INSTITUCIONAL, PROJETO PEDAGÓGICO INSTITUCIONAL, REGIMENTO GERAL E ESTATUTO}

Os instrumentos formais que materializam a existência da Universidade são o estatuto e o regimento geral. São eles que dão personalidade à organização. Nestes documentos que descobrimos para quê foi fundada a organização, quem pode participar das instâncias de tomada de decisão, de onde vêm os recursos e, o mais importante, quem são os beneficiados de suas ações, do seu trabalho.

Os estatutos contêm as regras gerais, filosofia e outros conteúdos. Já no regimento geral se encontram os procedimentos práticos e aspectos do dia a dia da Universidade.

Não existe um padrão único para estatutos e regimentos gerais. Cada organização tem liberdade de colocar o que quiser nestes instrumentos. Porém o que quer que seja colocado será lido pelos futuros interessados em participar da organização ou interessados em colaborar e pelos órgãos governamentais para fornecer subsídios, ajudas, verbas e doações. Por isso, é importante que o conteúdo destes instrumentos tenha visões claras, éticas e adequadas, mostrando que a organização possui comportamento ético elevado, ações realizadas com democracia e que a gestão dos recursos é realizada com transparência.

Constata-se que o estatuto e o regimento geral das Universidades não detalham formalmente suas estruturas administrativas, nem as competências e responsabilidades dos chefes, gerentes etc. Isto acaba ocorrendo por meio de portarias e resoluções do Conselho Universitário e do Reitor. Isto demonstra um valor maior dado pela comunidade para o lado acadêmico, em detrimento do administrativo, o que é de se esperar.

O Plano de Desenvolvimento Institucional (PDI) é um instrumentos ou peça que compõe o planejamento estratégico. O PDI deve ser um documento vivo, de consulta e referência para a comunidade. Abaixo um relato de alguns PDIs. 


\section{O PLANO DE DESENVOL VIMENTO INSTITUCIONAL E O PROJETO PEDAGÓGICO INSTITUCIONAL DE UNIVERSIDADES PÚBLICAS: LIMITES ORGANIZACIONAIS DOI: http://dx.doi.org/10.5007/1983-4535.2012v5n3p23}

Foram consultados Planos de Desenvolvimento Institucional (PDI) de algumas Universidades Federais. Um dos documentos consultados foi o PDI da Universidade Federal da Bahia (UFBA), neste documento a Universidade, inicialmente, define seu perfil institucional, missão e objetivos. As metas são definidas por áreas de atuação da Universidade (graduação, pós-graduação e pesquisa, extensão) e dizem respeito ao quinquênio 2004-2008.

Temos no PDI da UFBA a definição de objetivos e metas específicas em relação ao desenvolvimento de pessoas, reorganização administrativa, planejamento, orçamento, administração e finanças. Além disso, também são definidas a estrutura organizacional e instâncias de decisão, relações e parcerias com a comunidade, cooperação e parcerias com instituições e empresas, organização e gestão de pessoal.

Neste PDI foram incluídos o planejamento e organização didático-pedagógica. São definidos também os parâmetros para avaliação e acompanhamento do desempenho institucional. Para finalizar o documento são definidos os cronogramas de implantação do PDI para cada área de atuação da Universidade.

O Plano de Desenvolvimento Institucional (PDI) da Universidade Federal de São Carlos (UFSCar) possui estrutura e escopo diferentes quando comparados ao PDI da UFBA.

No início do documento são colocados os aspectos acadêmicos, organizacionais, ambientais e físicos da Universidade. Deste quadro dos diversos aspectos, a Universidade extraiu princípios, diretrizes gerais e específicas para o seu desenvolvimento. Há também o detalhamento das diretrizes específicas, que abordam os seguintes temas: processos de formação, ampliação, acesso e permanência na Universidade, produção e disseminação do conhecimento, capacitação dos servidores, ambiente, organização e gestão.

$\mathrm{Na}$ parte do documento que trata do "PDI em ação" são traçadas diretrizes para o desenvolvimento físico dos campi da UFSCar. Na finalização do PDI, são feitas observações sobre os conselhos superiores e definidas algumas propostas em relação à gestão das atividades de pesquisa da Instituição.

O PDI da Universidade Federal de Pernambuco (UFPE) começou a ser elaborado com a incorporação dos conteúdos presentes no Plano Estratégico Institucional, este tomou como ponto de partida as avaliações institucionais internas e externas. Deste modo, a partir do planejamento estratégico foram criadas três comissões de trabalho para, em conjunto com uma Coordenação Geral e Secretaria Executiva, operacionalizar o PDI. 


\section{O PLANO DE DESENVOL VIMENTO INSTITUCIONAL E O PROJETO PEDAGÓGICO INSTITUCIONAL DE UNIVERSIDADES PÚBLICAS: LIMITES ORGANIZACIONAIS DOI: http://dx.doi.org/10.5007/1983-4535.2012v5n3p23}

No início do PDI foi colocada a missão da Universidade, as áreas de atuação acadêmica. Também foram definidas as diretrizes para expansão e melhoria de qualidade do ensino de graduação e pós-graduação. O documento aborda diretrizes gerais e subjetivas para expansão e melhoria da qualidade.

Além das diretrizes gerais, o documento apresenta características próximas de um regimento interno com o estabelecimento de fluxo das atividades dentro da instituição e atribuições das áreas.

Em seu PDI, referente ao período de 2008 a 2012, a Universidade Federal de Minas Gerais (UFMG) descreve inicialmente sua missão e princípios institucionais, assim como, sua área de atuação, estrutura organizacional e instâncias e tomada de decisão.

Após esta descrição inicial, a Universidade traça planos, metas e ações para área de ensino de graduação, incluindo metas e ações específicas para as práticas acadêmicoprofissionais e avaliação do ensino. A mesma estrutura é replicada para área de pósgraduação, educação básica e profissional e extensão.

O documento também abrange os programas de intercâmbio para os estudantes da UFMG, com definição de metas específicas e ações a serem desenvolvidas. Há também políticas de equalização de oportunidades, mas quais são abordados temas como a assistência aos estudantes e programas de atendimento aos portadores de necessidades especiais.

A Universidade também definiu objetivos gerais em relação à gestão e planejamentos institucionais, que abordam desde a política de pessoal até a ampliação de estrutura física.

Nota-se na elaboração do PDI que há a definição de diretrizes gerais para a Instituição, onde não são contemplados projetos e ações específicos com maior detalhamento. Além disso, não foram definidos métodos de controle e avaliação da implementação das ações definidas no documento.

O PDI de 2005, afirma que todas as ações realizadas no âmbito da UNIFESP devem ser pautadas por um objetivo comum: a geração de conhecimentos socialmente referenciados. A real autonomia da UNIFESP pode ser projetada através de suas dimensões social e política, balizando justamente a sua capacidade em aplicar tais conhecimentos no atendimento à sociedade que a financia.

Também defende que uma administração eficiente da Universidade parte do envolvimento da comunidade acadêmica e da valorização das instâncias de decisão no 


\section{O PLANO DE DESENVOL VIMENTO INSTITUCIONAL E O PROJETO PEDAGÓGICO INSTITUCIONAL DE UNIVERSIDADES PÚBLICAS: LIMITES ORGANIZACIONAIS DOI: http://dx.doi.org/10.5007/1983-4535.2012v5n3p23}

equacionamento dos problemas da instituição. A tomada de decisão a partir do coletivo ajuda a determinar, articular e comunicar os valores que guiarão as escolhas da Universidade.

Além disso, são colocados no documento objetivos a serem cumpridos em um futuro muito próximo, são eles: manter e fortalecer os órgãos executivos e operacionais já existentes na administração da UNIFESP; dar continuidade aos processos de capacitação de recursos humanos para educação, extensão e pesquisa, formulando e implementando políticas institucionais de avaliação, prospecção e desenvolvimento; promover a capacitação da máquina administrativa e dos funcionários técnico-administrativos, na forma de programas e cursos de gestão financeira e estratégica; aprofundar a participação universitária na formulação de políticas públicas de saúde e nas novas áreas de expansão universitária, a nível nacional e internacional; criar um Departamento de Planejamento Estratégico em consonância com as políticas de regulação das atividades universitárias e de administração do Estado, com o objetivo de planejar, acompanhar, avaliar e divulgar as atividades de desenvolvimento a médio e longo prazos. Tal Departamento deve ser responsável por formular, implementar e avaliar, no âmbito da Universidade, os seguintes conjuntos de programas: planejamento estratégico e criação de ferramentas de política institucional; gerenciamento de projetos acadêmicos, programas colaborativos com o setor público, órgãos internacionais e setor privado; avaliação institucional e dos impactos das atividades universitárias, definindo ex ante e avaliando ex post os resultados; gestão estratégica de recursos humanos e gestão do conhecimento; capacitação para a gestão administrativa e financeira, de modo a que a instituição produza e aplique seus próprios instrumentos de estimação de recursos, score cards operacionais e análise de eficiência administrativa; fortalecimento da base teóricoconceitual das atividades descritivas da instituição: identificação de objetivos políticos, caracterização das relações com o seu entorno, identificação da configuração institucional e utilização de recursos e descrição organizativa; comunicação com a sociedade: identificação e divulgação, por diferentes meios de comunicação dos produtos científicos e tecnológicos; gerenciamento dos relatórios institucionais e identificação e proteção de inovações tecnológicas e da propriedade intelectual.

Deste modo, o PDI é um instrumento de pactuação dos vários interesses e demandas da Universidade. Nele são colocadas as demandas dos campi, escolas, cursos, departamentos, disciplinas e também dos professores pesquisadores funcionários técnicos administrativos e alunos. 


\section{O PLANO DE DESENVOL VIMENTO INSTITUCIONAL E O PROJETO PEDAGÓGICO INSTITUCIONAL DE UNIVERSIDADES PÚBLICAS: LIMITES ORGANIZACIONAIS DOI: http://dx.doi.org/10.5007/1983-4535.2012v5n3p23}

O PDI faz parte do processo de institucionalização (objetivação, habitualização e sedimentação) da Universidade, pois ele obedece a uma série de regras elaboradas colocadas pelo MEC que são obedecidas pela Universidade. Com isto temos uma normatização e formalização das atividades a serem desenvolvidas ao longo do tempo, levando a perpetuação e perenidade dos fluxos e das atividades fins da Universidade.

O PDI é um dos instrumentos de planejamento estratégico da Universidade que reflete o que a mesma pretende realizar nos próximos cinco anos. O instrumento é constituído de objetivos, justificativas, metas, ações, resultados esperados e indicadores.

O PDI também é um instrumento de gestão, pois por meio dele os executivos têm as ações a serem praticadas e as metas a serem atingidas num intervalo de tempo. Os indicadores servem como elementos balizadores das nossas ações e decisões a serem tomadas se estão no caminho correto ou não.

$\mathrm{Na}$ leitura dos PDIs observamos uma linguagem pouco objetiva e assertiva na maior parte dos PDIs, deixou-se a impressão que o PDI é um instrumento de discussão e não de direcionamento das atividades da instituição. Parece que é mais uma formalidade a ser entregue ao MEC como requisito ao comprimento das exigências educacionais.

Nota: foi entregue ao magnífico Reitor da UNIFESP a minuta de PDI 2011-2015, para discussão junto à comunidade. Procurou-se evitar os problemas relatados acima.

Foram também analisados alguns PPIs de Universidades Federais, segue abaixo:

Para a Universidade Federal da Bahia (UFBA) no Projeto Pedagógico Institucional o curso decide sobre as experiências que deverão ser desenvolvidas a partir de necessidades colocadas pelo aluno e pela sociedade, a partir de referenciais de natureza filosófica, política, econômica, cultural, científica, didático-pedagógica e técnica.

A Universidade utiliza como documento norteador a Resolução $n^{\circ} 02$ de 2000, do Conselho de Coordenação (atual CONSEPE). A mesma leva em conta também princípios como a flexibilidade, autonomia, articulação e atualização. Além disso, foi definido no corpo do PPI da UFBA o perfil profissional esperado do egresso da Universidade.

Como subsídio à elaboração dos Projetos Pedagógicos dos seus cursos de graduação, a UFBA aprovou a Resolução nº 05 de 2003, da Câmara de Ensino de Graduação.

Além dos itens acima, na parte final do documento são propostos alguns objetivos a serem alcançados no prazo de três anos em relação ao ensino na referida Universidade. 


\section{O PLANO DE DESENVOL VIMENTO INSTITUCIONAL E O PROJETO PEDAGÓGICO INSTITUCIONAL DE UNIVERSIDADES PÚBLICAS: LIMITES ORGANIZACIONAIS DOI: http://dx.doi.org/10.5007/1983-4535.2012v5n3p23}

A Universidade Federal de Minas Gerais inicia seu PPI explicitando como deve ser conduzida a ação pedagógica na referida Universidade. Também afirma que a composição do PPI deve ocorrer a partir da política curricular institucional, consubstanciada no princípio de flexibilidade curricular, conforme disposto na Manifestação do Conselho de Ensino, Pesquisa e Extensão.

No documento, observa-se a preocupação com a criação de condições que permitam ao aluno uma crescente interação com os processos sociais de uma forma mais geral.

Além do conteúdo acima citado, também foram definidos no PPI onze princípios norteadores da instituição. A proposta é que após a publicação e divulgação do PPI, a Universidade estabeleça diretrizes pedagógicas mais específicas, capazes de traduzir no cotidiano os onze princípios colocados anteriormente.

Para finalizar o documento foram citadas algumas metas qualitativas e ações gerais para o cumprimento dos princípios do PPI.

No início de seu Projeto Pedagógico Institucional, a Universidade Federal de Santa Catarina apresenta a forma como a instituição insere-se regionalmente, em especial no Estado de Santa Catarina. Nas duas seções seguintes, foram apresentados os princípios filosóficos e técnico-metodológicos gerais que norteiam as práticas acadêmicas e a organização didáticopedagógica da Universidade.

Na principal seção do documento, apresentam-se as políticas, objetivos e metas para as diferentes áreas de atuação ou dimensões da Universidade, tendo como base o período de vigência do PPI. Por fim, faz-se a síntese de várias metas no contexto do atendimento da responsabilidade social da UFSC.

$\mathrm{Na}$ apresentação do documento de 2006, a UNIFESP afirma que o PPI é uma carta de intenções que resulta dos esforços coletivos de discussão acerca dos propósitos que animam a Universidade nas suas atividades relacionando-se com a sociedade brasileira.

A UNIFESP também afirma que traz no conteúdo do projeto os instrumentos para provocar, juntamente com o Plano de Desenvolvimento Institucional (PDI) e com outros instrumentos de política institucional, a redefinição de práticas acadêmicas. Estas abrangem a forma como o conhecimento gerado nas instituições de ensino superior se difunde, provocando a melhoria de condições de vida da população brasileira. 


\section{O PLANO DE DESENVOL VIMENTO INSTITUCIONAL E O PROJETO PEDAGÓGICO INSTITUCIONAL DE UNIVERSIDADES PÚBLICAS: LIMITES ORGANIZACIONAIS DOI: http://dx.doi.org/10.5007/1983-4535.2012v5n3p23}

$\mathrm{Na}$ introdução do PPI realizou-se um contexto histórico da Universidade, suas especificidades e abrangência de atuação. É importante ressaltar, que é dedicado um capítulo à concepção curricular e pedagógica da expansão universitária.

Além da missão institucional da UNIFESP também são citados os princípios norteadores do projeto pedagógico. Deste modo, grande parte do documento é dedicada à descrição do perfil profissional a ser formado nos cursos oferecidos pela instituição e aos princípios direcionadores dos cursos. Foram realizadas as mesmas considerações para a pósgraduação stricto sensu e programas de extensão.

No final do documento foram definidos objetivos gerais em relação ao sistema de capacitação de funcionários e pessoal técnico-administrativo.

\section{ANÁLISES FINAIS}

Fica evidenciada na leitura dos planos PDIs e PPIs a necessidade de uma estrutura organizacional para a sua implantação e também uma necessidade de um maior detalhamento das informações em termos concretos do contexto analisado. A literatura analisada também ratifica a necessidade de uma estrutura organizacional desenhada e fluxos de informações para alimentar o processo de tomada de decisões e ações. O planejamento é concepção e execução, os instrumentos analisados são parte deste processo.

A concepção dos modelos, planos, projetos e estratégias esperam por uma execução e esta demanda uma estrutura organizacional consistente e alinhada nos três níveis institucional, departamental e operacional das Universidades.

Portanto, a institucionalização das atividades é um processo consensual e de importância vital para organizar o crescimento e consolidar os avanços obtidos. Acredita-se que o meio acadêmico ainda não valoriza esta questão.

Finalmente, os limites deste trabalho encontram-se nas particularidades de cada instituição na aplicação destes instrumentos, que são a cultura e o contexto onde elas estão operando.

\section{BIBLIOGRAFIA}

BERGER, P.; LUCKMANN, T. Social Construction of Reality. Nova Iorque: Anchor Books, 1967.

CECILIO, L. C. de O. Pensando o Planejamento na Universidade. RAE-Revista de Administração de Empresas - FGV/EAESP, São Paulo, v.8, n.2, 2-7, 2001. 


\section{O PLANO DE DESENVOL VIMENTO INSTITUCIONAL E O PROJETO PEDAGÓGICO INSTITUCIONAL DE UNIVERSIDADES PÚBLICAS: LIMITES ORGANIZACIONAIS DOI: http://dx.doi.org/10.5007/1983-4535.2012v5n3p23}

CHANDLER, A. D. Strategy and Structure. Cambridge, MA: MIT Press, 1962.

DAVENPORT, T.; HARRIS, J. G. Competição Analítica: vencendo através da nova ciência. Rio de Janeiro: Campus, 2007.

FACHIN, R. C.; HARDY, C. Gestão estratégica na Universidade brasileira: teoria e casos. Porto Alegre: Ed. UFRGS, 1996. 222 p.

GIDDENS, A. Central problems in social theory: action, structure, and contradiction in social analysis. California: Berkeley, 1979.

HAMEL, G.; PRAHALAD, C. K. Competindo pelo futuro: estratégias inovadoras para obter o controle do seu setor e criar os mercados de amanhã. Rio de Janeiro: Campus, 1995.

HREBINIAK, L. G. Fazendo a estratégia funcionar: o caminho para uma execução bemsucedida. Porto Alegre: Bookman, 2006. 368 p.

LERNER, A. A Strategic Planning: Primer for Higher Education. Califórnia State. University. Califórnia: College of Business Administration and Economics, 1999.

MAXIMIANO, A. C. A. Teoria Geral da Administração: da escola científica à competitividade na economia globalizada. $2^{a}$ edição. São Paulo: Atlas, 2000. 546p.

MEYER, J.; ROWAN, B. Institutionalized organizations: formal structure. American Journal of Sociology, 1979.

MINTZBERG, H. Criando organizações eficazes - estruturas em cinco configurações. São Paulo: Atlas, 1995.

MINTZBERG, H. Ascensão e queda do planejamento estratégico. Porto Alegre: Bookman, 2004. 259p.

MINTZBERG, H.; QUINN, J. B. O processo da estratégia. $3^{\mathrm{a}}$ edição. Porto Alegre: Bookman, 2001. 404p.

PICCHIAI, D. Estratégia, estrutura e competências: estudo de caso de três operadoras de planos de assistência à saúde modalidade auto gestão. Relatório 17/2008. GV-Pesquisa EAESP-FGV, 2008.

RAMOS, L. C. S.; REZENDE, D. A. A aplicação do business intelligence na gestão pública. In: XXIV ENCONTRO NACIONAL DE ENGENHARIA DE PRODUÇÃO, 2004. Florianópolis, Brasil.

RIZZO, G. A.; ORANDI, M. F. Estrutura Informacional para monitoramento do Planejamento Estratégico apoiado no Balanced Scorecard. Revista Eletrônica de Gestão de Negócios - Universidade Católica de Santos, Santos, v.2, n.2, 113-137, 2006. 
SINK, D. S.; TUTLE, T. C. Planejamento e medição de performance. Rio de Janeiro: Qualitymark, 1993.

WILLIAMSON, O. E. The Economic Institutions of Capitalism. New York: The Free Press, 1985.

YIN, R. K. Estudo de caso: planejamento e métodos. $3^{\text {a }}$ edição. Porto Alegre: Bookman, 2005. 212 p.

\section{SITES}

PDI - UFBA: Disponível em < http://www.proplad.ufba.br/docs/PDI2004-20081.PDF>. Acesso em 27/09/2010.

PDI - UFSCar: Disponível em < $<$ http://www.ufscar.br/pdi2002/principios_e_diretrizes.pdf $>$. Acesso em 27/09/2010.

PDI - UFPE: Disponível em < $<$ http://www.ufpe.br/proplan/images/pdi\%20 divulgacao.pdf $>$. Acesso em 27/09/2010.

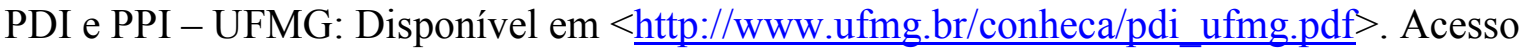
em $27 / 09 / 2010$.

PPI - UFBA: Disponível em < $<$ http://www.proplad.ufba.br/proj_pedag_institucional.pdf $>$. Acesso em 27/09/2010.

PPI - UFSC: Disponível em $<\underline{\text { http://pdi.paginas.ufsc.br/files/2010/05/2.-Projeto- }}$

Pedagógico.pdf>. Acesso em 27/09/2010.

PPI - UNIFESP: Disponível em $<$ http://www.unifesp.br/prograd/portal/index.php?option=com content\&view $=$ article\&id=64: documentos-unifesp\&catid $=24 \&$ Itemid $=67>$.

Acesso em 27/09/2010. 